\title{
"Sobre las traducciones". El pensamiento traductológico británico en Chile a partir de una traducción de Andrés Bello (1838)
}

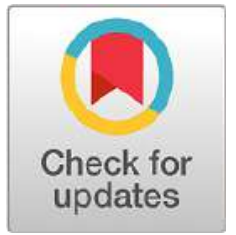

\section{Resumen}

El trabajo que se presenta aquí estudia el contexto de producción de una traducción de autoría de Andrés Bello. E1 texto fuente es una reseña del abogado escocés George Moir, publicada en The Edinburgh Review (1837), de una traducción inglesa de una obra de Schiller, que abarca, de manera preliminar, aspectos del pensamiento traductológico en Europa, a través de la obra de traductores como Dryden, Pope y Schlegel. Los extractos de la reseña fueron traducidos para el periódico chileno El Araucano (en agosto de 1838), en un artículo sin firma, con el título de "Sobre las traducciones". El cotejo de esta traducción con el texto original permite perfilar la autoría de Bello, por ejemplo, con relación a las estrategias que adoptó para traducir el texto al castellano, que posibilitan apreciar los gestos irónicos indirectos presentes en su traducción. Estas ayudan a delimitar la evolución de su pensamiento respecto a la práctica de traducir. Se concluye que esta traducción inédita de Bello sería el primer caso de divulgación, en la prensa chilena del siglo XIX, del pensamiento traductológico.

Palabras clave: Andrés Bello, El Araucano, George Moir, The Edinburgh Review, teoría de la traducción en Chile.

\section{"On Translations": British Translation Theory in Chile From a Translation by Andrés Bello (1838)}

\begin{abstract}
This article focuses on the setting of a translation produced by Andrés Bello. The source text is a review allegedly written by Scottish lawyer George Moir of a Schiller's essay translated into English, which includes a cursory overview of certain aspects of European translation theory based on the works of translators such as Dryden, Pope, and Schlegel. The review appeared published in The Edinburgh Review (1837), and certain extracts were translated for the Chilean newspaper El Araucano (in August 1838) as an anonymous article entitled "Sobre las traducciones" (On Translations). The comparative reading of this translation with the source text allows to evince Bello's authorship, for example, in terms of the translation strategies he employed, which made visible several indirect ironic gestures in his work. This irony sheds light on the development of Bello's reflection upon the practice of translation. Therefore, this study concludes that this
\end{abstract}

1 Este trabajo se deriva de la tesis de maestría titulada "La traducción literaria en los hermanos Manuel Antonio y Guillermo Matta Goyenechea (1845-1864)” y realizada en el Magíster en Estudios Literarios y Culturales Latinoamericanos de la Pontificia Universidad Católica de Valparaíso. 
unknown work translated by Bello is seemingly a first instance of bringing translatological thinking to the general public through Chilean press in the $19^{\text {th }}$ century.

Keywords: Andrés Bello, translation theory in Chile, El Araucano, The Edinburgh Review, George Moir.

«Sur les traductions ». La pensée traductologique britannique au Chili à partir d'une traduction réalisée par Andrés Bello (1838)

\section{Résumé}

Le présent travail est consacré au contexte de production de l'une des traductions faites par Andrés Bello. Le texte source est un compte-rendu rédigé par l'avocat écossais George Moir et publié dans The Edinburgh Review en 1837, dont quelques extraits furent traduits pour le journal chilien El Araucano (août 1838) dans un article sans signature intitulé « Sobre las traducciones » (Sur les traductions). L'original - le compte-rendu d'une traduction anglaise de Schiller —, analyse quelques aspects de la pensée traductologique en Europe à partir notamment des ouvrages de traducteurs tels que Dryden, Pope et Schlegel. La confrontation de cette traduction à l'original - à cause des stratégies utilisées pour rendre le texte en espagnol et les gestes ironiques indirectes présents dans la traduction - nous permet d'envisager qu'il s'agit bien d'un texte de Bello. À l'aide de cette comparaison, il nous serait donc possible de délimiter l'évolution de sa pensée sur la pratique de traduction. Nous arrivons également à la conclusion que cette traduction inédite de Bello est le premier cas de divulgation - dans la presse chilienne - d'une pensée traductologique.

Mots-clés : Andrés Bello, théorie de la traduction en Chili, El Araucano, The Edinburgh Review, George Moir. 


\section{Introducción}

El intelectual venezolano Andrés Bello (17811865) es una figura histórica ineludible en el estudio de la traducción literaria en Sudamérica durante la primera mitad del siglo XIx. Su figura fue clave en la aparición del periódico chileno El Araucano, publicado y financiado con apoyo gubernamental entre 1830 y 1877 (Jaksic, 2010; Silva Castro, 1965). Como ha señalado Juan Poblete (2013), Bello, junto a otros intelectuales americanos del periodo, se vio a sí mismo como "un activo traductor, un reelaborador original de conocimientos y prácticas elaboradas" (p. 109).

El Grupo de Investigación sobre Historia de la Traducción en América (HISTAL) ha gestado una historiografía que destaca a la práctica traductora durante el siglo XIX como poseedora de un componente creativo (Arroyave, 2013; Pomerlau et al., 2016). En este componente también se vislumbra la identificación de una tendencia que ha sido denominada "apropiación", definida como una

[...] modalidad creativa de la traducción tendiente a consolidar la identidad de la colectividad a la que pertenece el traductor. Es también un proceder selectivo en el que el traductor escoge sólo lo que resulta útil para sus propósitos (Bastin et al., 2004, p. 72).

Para Andrés Bello, traducir era una táctica, en la medida en que los "letrados hispanoamericanos carecían de una posición claramente definida y reconocida por la autoridad europea para negociar [...] traducir era parte fundamental del proceso de construcción de identidades culturales nacionales" (Pagni, 2003, pp. 340-341). Asimismo, en su rol como mediador cultural, Bello generó incipientes debates sobre diversas problemáticas, que recorren aspectos de la literatura moderna y de la crítica literaria de su época.

Algunos estudios sobre Bello han evidenciado que se dedicó especialmente a la traducción de poetas franceses, como Jacques Delille y Víctor Hugo, además de poner en práctica un estilo literario de carácter "imitativo"; pero, a medida que traducía e imitaba los modelos poéticos, el traductor entraba, a su vez, en un proceso creativo, por medio del acto de apropiación (Pagni, 2003, 2004; Valero, 2001). En el caso de Bello, se ejemplifica con su imitación del poema "Les Jardins" de Jacques Delille, donde la práctica de traducir los términos del poema original para el lector americano se vuelve "una especie de prestación de servicio al original" (Pagni, 2003, p. 353). Estas imitaciones poéticas se plantean a partir de una idea fundante para el traductor hispanoamericano del siglo xIx:

En sus poemas y traducciones los criollos cultos no sólo pudieron entrar en contacto con los autores extranjeros, sino que experimentaron también el amor por el suelo americano [...]. La incorporación de lo americano en sus traducciones [es] uno de los factores que marca el tipo de traducción que practicó Bello. Un hecho que sin dudas ejerció gran influencia en los hombres de acción de la época, quienes aprendieron en sus escritos a amar y valorar el continente en el que habían nacido (Bastin et al., 2004, p. 81).

Por lo tanto, la traducción en Bello no debe ser entendida como una práctica literaria pasiva y de segundo orden, sino que debe asumirse como una actividad altamente creativa, como bien señalan Susan Bassnett y Harish Trivedi en la introducción de Post-colonial Translation. Theory and Practice:

La traducción es una actividad altamente manipulativa que involucra todo tipo de etapas en ese proceso de transferencia a través de fronteras lingüísticas y culturales. Lejos de ser una actividad inocente y transparente, la traducción está cargada de significación en cada etapa; raramente, a lo mejor nunca, involucra una relación de igualdad entre textos, autores o sistemas $(1999$, p. 2$){ }^{2}$

2 "Translation is a highly manipulative activity that involves all kinds of stages in that process of transfer across linguistic and cultural boundaries. 
Un traductor no se encuentra aislado de su propio contexto temporal o cultural. De acuerdo con la investigadora Andrea Pagni, la traducción se asimila a "un laboratorio de escritura", donde colisionan no solo textos, sino que también contextos: el del texto que se traduce como también el que rodea al texto traducido. Por lo tanto:

A fin de encontrar explicaciones de estas diferencias es útil, como digo, comparar los contextos en que se producen respectivamente el texto fuente y la traducción, porque el texto traducido funciona dentro de otro sistema y funciona de otra manera. No se trata, esto es para mí muy claro, de comparar para determinar si la traducción es buena, regular o mala [...] sino para intentar explicar por qué una traducción es cómo es. $Y$ para encontrar posibles respuestas, tengo que ir a los contextos literarios, culturales, políticos y sociales, en los que se produjeron los textos (Domínguez, 2018, p. 126).

Es a través del cotejo de los contextos y de los textos que pueden identificarse las diversas estrategias y manipulaciones mediante las cuales el traductor alcanza los objetivos que se propone. De acuerdo con Lawrence Venuti (2000), se trataría de un proceso que nunca es transparente, dado que el traductor modifica y acomoda, en mayor o menor medida, los textos fuente a los contextos receptores, para garantizar su efectividad de sentido. Venuti afirma que

La traducción nunca se comunica de manera inalterada, ya que el traductor negocia las diferencias lingüísticas y culturales del texto foráneo, reduciéndolas e incorporando otro conjunto de diferencias básicamente domésticas, tomadas de la lengua y la cultura receptoras, a fin de permitir que lo foráneo pueda ser acogido $(2000$, p. 468$){ }^{3}$

Translation is not an innocent, transparent activity but is highly charged with significance at every stage; it rarely, if ever, involves a relationship of equality between texts, authors or systems". Todas las traducciones de aquí en adelante son del autor.

3 "Translation never communicates in an untroubled fashion because the translator negotiates the
Estas ideas conectan con los planteamientos de Bassnett y Trivedi (1999), quienes señalan que la traducción "no ocurre en un vacío, sino que en un continuo; no es un acto aislado" (p. 2). Más allá de considerar "la traducción como una apropiación, consistente en suscitar un desplazamiento de autoría o de propiedad" (Bastin et al., 1999, p. 70).

Otra perspectiva de aproximación es la que destaca Gertrudis Payàs, quien señala que la traducción es un modo de adquisición, tanto de formas, géneros y estilos como de contenidos e ideas; por lo tanto, la traducción permite visibilizar "el consumo intelectual de una sociedad, que se alimenta de obras extranjeras" (Payàs, 2007, p. 38). Durante la primera mitad del siglo XIX, las sociedades hispanoamericanas, entre ellas la chilena, que es el contexto que se estudia en este trabajo, se caracterizan por ser periféricas en relación con las metrópolis europeas y estadounidense. Esta característica de marginalidad permite que se ejerza una voracidad intelectual para asimilar textos foráneos:

Una sociedad periférica como la chilena aprovecha la lejanía geográfica y el desinterés intelectual de Europa por lo que se hacía en Hispanoamérica para ejercer el derecho de apropiarse, siempre en función de sus necesidades, reales o presuntas, de sus creaciones intelectuales (Payàs, 2007, p. 38).

Por lo tanto, la necesidad de adquirir textos genera una constante apropiación de otros trabajos, para así suplir su falta; esto incluye el acto de adueñarse de estilos ajenos, para adecuarlos al contexto de la sociedad receptora:

Por su carácter de reproductoras de otros textos, a los que la mayoría de los lectores no tiene

linguistic and cultural differences of the foreign text by reducing them and supplying another set of differences, basically domestic, drawn from the receiving language and culture to enable the foreign to be received there". 
acceso, [las traducciones] implican la posibilidad de adueñarse de materiales y estilos ajenos, sea adecuándolos a lo que en la sociedad receptora es admisible, pensable o decible, sea aprovechándolos para introducir innovaciones. Por eso podemos utilizar las traducciones como una de las puertas de entrada a la historia intelectual (Payàs, 2007, p. 38).

Esta investigación incursiona en un aspecto que no ha sido muy estudiado en la historia de la traducción: la reconstrucción del contexto de producción de las traducciones publicadas en la prensa hispanoamericana de la primera mitad del siglo XIX. Gertrudis Payàs, en su edición del texto Biblioteca chilena de traductores, publicada originalmente en 1924 por el bibliógrafo e investigador chileno José Toribio Medina (1852-1930), ${ }^{4}$ respecto a la importancia de indagar en las abundantes traducciones publicadas en la prensa que permanecen inexploradas, menciona que

Deberíamos agrandar el objetivo e incluir, en un lugar muy principal, el estudio de las traducciones de la prensa, que está por hacerse. La traducción en la prensa, tanto por las características de ese medio como por su importancia crucial en el periodo de referencia, nos daría la medida del consumo "en tiempo real" de las producciones intelectuales en otras lenguas [...] la traducción en la prensa, que tenía sus originales en la prensa extranjera, o en fragmentos selectos de obras publicadas, sería mucho más ilustrativa de esta inmediatez de consumo (Payàs, 2007, p. 39).

4 La Biblioteca chilena de traductores, de José Toribio Medina, como bien señala Gertrudis Payàs en su “Estudio preliminar”, es “un sencillo catálogo de traducciones, ordenadas primero por año y luego por apellido del traductor, en el que consigna solamente los datos bibliográficos de la obra sin aportar ningún comentario de fondo [...] no se preocupa por indagar los autores y títulos de los textos originales, que figuran en la obra sólo si constan en la portada de la traducción que ahí se transcribe. En ella hay, pues, trescientas diecisiete entradas sin nombre de autor original, y no aparece prácticamente nunca el título de la obra original” (Payàs, 2007, p. 30).
Si bien la figura de Bello ha sido estudiada con detalle en los trabajos anteriormente mencionados, estimamos que no se han abordado todavía, con la debida atención, algunos de sus textos vinculados con la traducción como tema de reflexión. Una revisión del archivo de la prensa chilena entre 1830 y 1838 ha traído a la luz un breve artículo publicado en las páginas de un periódico en cuya redacción Bello participó activamente en Chile. Sin embargo, la evidente dificultad de identificar la autoría en las traducciones publicadas en la prensa complejiza la tarea de rastrear el "consumo del tiempo real", dado que en su mayoría eran artículos anónimos.

Por lo tanto, este trabajo se aproxima a este desafío del estudio de la traducción de artículos en la prensa durante el siglo XIX, presentando como caso de estudio una traducción, publicada en El Araucano en agosto de 1838, de una reseña impresa en The Edinburgh Review en 1837. El autor del texto fuente, de acuerdo con The Wellesley Index to Victorian Periodicals 1824$1900,{ }^{5}$ sería el abogado y escritor escocés George Moir (1800-1870), quien habría publicado la reseña para comentar una reciente traducción inglesa de George Irvine de la tragedia Die Braut von Messina, del poeta alemán Friedrich Schiller (Houghton et al., 1989, pp. 547-548).

El artículo expone, en primer lugar, el contexto del autor del texto fuente, dando referencias biográficas de la trayectoria del reseñador, como también el ambiente cultural que rodeaba a la publicación británica durante las décadas de los veinte y de los treinta del siglo xIX, principalmente sobre el pensamiento traductológico.

En segundo lugar, se presenta la trayectoria de Bello en sus años de permanencia en Londres,

5 La obra The Wellesley Index to Victorian Periodicals 1824-1900 permite identificar a algunos de los autores de las reseñas anónimas publicadas en las diversas reviews británicas. En aquella se publicó una bibliografía de las reseñas escritas por George Moir en la prensa británica durante gran parte del siglo XIX.. 
en especial en la década de los veinte, cuando la lectura y su acercamiento al mundo periodístico británico, principalmente el desarrollado en torno a la publicación de revistas de reseñas, habría gestado en su práctica intelectual un modelo de periodismo crítico-literario que utilizaría en sus propios proyectos.

Lo anterior se articula luego con el contexto histórico del modelo periodístico crítico-literario adaptado por Bello al incipiente campo literario chileno, desde su posición de redactor de El Araucano desde el año 1830 en adelante. Además, se exponen los fundamentos que permiten adjudicar la autoría de esta traducción a Andrés Bello.

Por último, se presenta un cotejo entre el texto fuente publicado en The Edinburgh Review y la traducción de Bello, para visualizar las estrategias, selecciones y omisiones llevadas a cabo por Bello, bajo la figura de un reseñador latinoamericano. Esta categoría ayuda a identificar la traducción realizada por Bello como una práctica de lectura, escritura y traducción que necesariamente manipula el texto fuente, para adaptarlo en un texto ensayístico destinado al lector chileno.

Se trata de una traducción que tiene un carácter divulgativo, junto con un recorrido panorámico de reflexiones sobre la traducción en autores británicos y alemanes. El periódico chileno, durante esa época, pretendía suplir necesidades temáticas, en especial buscaba crear una literatura de cuño nacional, dentro un contexto poscolonial.

Al final del texto se adjunta una transcripción de la traducción y su original (véanse Anexos 1 y 2).

\section{La trayectoria literaria de George Moir y The Edinburgh Review}

El abogado y escritor George Moir nació en Aberdeen, en 1800. Fue en esta ciudad donde inició sus estudios de leyes. Sin embargo, la necesidad de buscar también una formación avanzada en literatura y, eventualmente, una posible carrera literaria, fue lo que determinó en Moir la decisión de mudarse a Edimburgo en 1824, ciudad donde juraría como abogado en 1825 .

Este acercamiento a las llamadas "literaturas modernas", principalmente del sur de Europa, llevó a Moir al estudio y a la adquisición de idiomas como el español y el francés, interesándose en particular en la antigua literatura española (Murdoch Lawrance, 1913, p. 337; Neaves, 1871, p. 109). Su interés por esta literatura se manifiesta en sus primeras publicaciones en la prensa literaria victoriana. Por ejemplo, la trayectoria de Moir en el ámbito de la crítica y de los estudios literarios se inicia en forma temprana, en el año 1822, cuando publica su primera reseña de poesías antiguas españolas en The New Monthly Magazine and Literary Journal, con el título de "Selections from Ancient Spanish Poetry"6 (Moir, 1822, pp. 407-414).

En 1824, Moir comienza a aprender alemán y a estudiar la literatura en esta lengua, estimulado por los consejos del profesor escocés de lógica y metafísica sir William Hamilton (1788-1856). De acuerdo con las notas manuscritas de Moir, proporcionadas por él mismo al biógrafo de Hamilton, John Veitch, que describen el encuentro entre Moir y Hamilton:

Una consulta literaria fue el motivo que inició la cálida y perdurable amistad entre sir William y el Sr. George Moir. En 1824, el Sr. Moir, en ese entonces un joven que se preparaba para recibirse de abogado, estaba inmerso en la redacción de un artículo para la Edinburgh Review sobre la antigua balada lírica de España. Fue alentado por un amigo en común, Thomson of Bachory, para consultarle a sir William por referencias sobre la materia, como también por los numerosos libros que se

6 A lo largo de este texto, Moir comenta y traduce extractos del tomo primero de Floresta de rimas antiguas castellanas, de Juan Nicolas Böhl de Faber, publicado en 1821 (Moir, 1822, p. 407). 
habían publicado en Alemania sobre el tema [...]. "Confieso", dice el Sr. Moir, "que, de antemano, la entrevista me pareció formidable [...] él no solo demostró un vivo interés en mi reseña, sino que, como yo no entendía alemán en ese momento, me explicó el significado de los pasajes de las obras alemanas relacionadas con el tema" (Veitch, 1869, pp. 131-132). ${ }^{7}$

Naturalmente, la recomendación de Hamilton se encontraba condicionada por el gran influjo de los escritores alemanes en el llamado "Renacimiento romántico" de Europa.

Cabe mencionar aquí las palabras de Edgar Allison Peers, quien señalaba, respecto al romanticismo español, que "toda exposición del renacimiento romántico en España no sólo sería incompleta sin hacer referencia a Alemania, sino que [también], de las influencias extranjeras que sufrió, la de Alemania aparece lógicamente en primer término" (1954, p. 147).

Además, la mención sobre "un artículo para la Edinburgh Review" está relacionada con que Moir publicaría sus primeros dos artículos de reseñas en dicho medio ese mismo año. El primero apareció en enero de 1824, como "Early Narrative and Lyrical Poetry of Spain"8 (Moir,

7 El texto original señala: "A literary consultation was the occasion of the commencement of the warm and lifelong friendship which subsisted between Sir William and Mr. George Moir. In 1824 Mr. Moir, then a young man preparing to pass advocate, was engaged on an article for the 'Edinburgh Review' on the ancient ballad poetry of Spain, and was encouraged by a mutual friend, Mr. Thomson of Bachory, to apply to Sir William for information on the subject, and on the numerous books that had appeared in Germany in reference to it [...] 'I confess,' says Mr. Moir, 'the interview appeared to me beforehand rather a formidable one. [...] He not only took a warm interest in my review, but, as I did not then understand German, explained to me the meaning of passages in the German works bearing on the subject".

8 El texto comentaba tres obras: la primera fue la ya reseñada anteriormente Floresta de rimas antiguas 1824a, pp. 393-432). El segundo artículo, publicado en julio de 1824, llevó por título "Lyric Poetry of Spain" (Moir, 1824b, pp. 443-476). ${ }^{9}$ En esta última reseña, Moir comenta, en los siguientes términos, una traducción inglesa de los poemas de Garcilaso de la Vega:

La égloga ha sido traducida con peculiarbelleza por el sr. Wiffen, cuyo elegante volumen debe ser considerado como una gran adquisición para el estudioso hispanista. Sus traducciones se elevan del mismo modo respecto al tema y ha demostrado una muy considerable destreza para interpretar con fidelidad, pero de mejor forma, algunos de estos pasajes en prosa que se encuentran aquí y allá en muchos poemas de Garcilaso [...] la traducción del Sr. Wiffen presenta una idea bastante fiel de la melancólica belleza del original (Moir, 1824b, p. 457). ${ }^{10}$

Dichos trabajos contenían nuevamente traducciones al inglés hechas por Moir de extractos de las poesías hispanas publicadas en estas recopilaciones. En 1827, Moir publicaría de manera

castellanas de Böhl de Faber; la segunda, Silva de viejos romances, una compilación de antigua literatura española publicada en Viena en 1815 por Jacob Grimm, mientras que la tercera fue Sammlung der besten Alten Spanischen, Historischen, Ritter und Maurischen Romanzen, publicada en 1817 por el historiador francoalemán Georges Bernard Depping (1784-1853), en Leipzig (Moir, 1824a, p. 393).

9 En esta reseña, Moir comentó dos obras sobre poesía y romances españoles: el segundo tomo de Floresta de rimas antiguas, de Böhl de Faber, y la traducción inglesa de J. H. Wiffen de las obras del poeta español Garcilaso de la Vega (1503-1536), publicada en 1823 (Moir, 1824b, p. 443).

10 "This Eclogue has been translated with peculiar beauty by Mr. Wiffen, whose elegant volume must be regarded as a great acquisition to the Spanish scholar. His translations uniformly rise with the subject; and he has shown very considerable dexterity in rendering with fidelity, yet in an improved shape, some of those prosing passages which occur here and there in many of Garcilaso's poems [...] Mr. Wiffen's translation presents a very faithful idea of the melancholy beauty of the original". 
anónima su traducción del Wallenstein, de Friedrich Schiller. Su traducción contó con las revisiones y correcciones efectuadas por William Hamilton al manuscrito, quien le brindó consejos sobre la forma adecuada de traducir:

Sir William amablemente revisó y corrigió las páginas con tal paciencia y cuidado como si fueran de su propia autoría [...]. Su consejo era siempre "traduzca tan literal como le sea posible, evite las expresiones perifrásticas; incluso hasta lo que no suena bien es mejor que cualquier desviación del original" (Veitch, 1869, p. 132). ${ }^{11}$

En los consejos brindados por Hamilton, más en el contenido de la reseña de la traducción de Wiffen, queda patente la impronta de la literalidad como principio base en la evaluación de una traducción "adecuada". Es decir, se presenta una afinidad hacia un método de traducción con base en la fidelidad literal, en desmedro de la fidelidad al sentido.

En 1828, Moir publica su contribución a una obra colectiva del editor escocés Archibald Constable, con una traducción de dos volúmenes de The Historical Works of Frederick Schiller. Publicaría también numerosos ensayos de reseñas en otra revista británica de reseñas de libros extranjeros, The Foreign Quarterly Review, fundada en 1827. Robert Pearse Gillies escribe sobre la gestación de la revista en sus Memoirs of a Literary Veteran: "Como un colaborador y consejero, mi amigo el Sr. George Moir era muchos en uno. Dominaba diversos idiomas, su gusto crítico era agudo, su paciencia era inacabable" (1851, p. 161). ${ }^{12}$ Por lo tanto, la amistad de Moir

11"Sir William kindly revised and corrected the sheets with as much patience and care as if they had been his own composition [...] His advice always was: Translate as literally as possible avoid periphrastic expression; even roughness is better than any departure from the original".

12 "As a collaborator and adviser, my friend, Mr. George Moir, was in himself a host. He had command of diverse languages, his critical taste was acute, his patience was unconquerable". con el editor Gillies fue clave para impulsar esta publicación durante la década de los treinta. Además, en los escritos de Gillies se evidencia que el campo literario escocés de la época recorría inevitablemente un camino incesante de traducciones y comentarios literarios: "Mi objetivo principal en el cultivo del idioma extranjero era demostrar la existencia de tesoros, hasta entonces desconocidos e insospechados, sacar a la luz gemas y filones cuya misma existencia se había negado" (1851, p. 162). ${ }^{13}$

Naturalmente, este afán era compartido de igual manera por Moir, quien contribuyó, en esta publicación de Edimburgo, con un especial foco temático en la literatura extranjera. Su contribución quedaría plasmada en diversas reseñas, publicadas entre 1827 y 1833 , que adquirían más bien la forma de ensayos literarios de divulgación de literatura contemporánea francesa, italiana y alemana.

En 1835, Moir obtendría la posición de catedrático de "Retórica y Bellas Letras" de la Universidad de Edimburgo. Se trata de la misma cátedra que fuera fundada por una figura clave en la Ilustración escocesa, el presbítero y autor escocés Hugh Blair (1718-1800), autor de las célebres Lectures on Rhetoric and Belles Lettres, publicadas en 1783, que, según Barry L. Velleman, fueron consideradas, durante la primera mitad del siglo XIX, como "una obra de gran influencia en la enseñanza de la retórica en Chile" (1995, p. 34). Se debe agregar que Andrés Bello fue un ávido lector de Blair y un gran admirador de su obra; poseía ejemplares de la edición de 1825 de este texto, de acuerdo con el catálogo de su biblioteca privada (Velleman, 1995).

Sin embargo, desde 1835 en adelante, Moir combinaría su trabajo en la cátedra de la universidad con la publicación de reseñas literarias

13 "My own leading object in the cultivation of foreign language, was to demonstrate the existence of treasures hitherto unknown and unexpected, to bring out of the dark mine gems and ore -the very existence of which had been denied". 
en la prensa británica. Sería en el año 1837 cuando publicaría, en The Edinburgh Review, una reseña de la reciente traducción inglesa, realizada por George Irvine, de la obra dramática "La novia de Messina", de Schiller.

Moir era un referente ineludible en literatura alemana en el campo literario británico del periodo; su experiencia como traductor de Schiller y su posición universitaria en Edimburgo le permitían establecerse como una autoridad en materia de traducción. Dado esto, Moir evaluaría la traducción de Irvine, en términos generales, en su reseña publicada en The Edinburgh Review, de la siguiente forma:

Estimamos que la traducción de este poema, de parte del sr. Irvine, es sumamente meritoria y, en general, es un exitoso intento de transmitir al lector inglés una idea sobre este drama coral. Si bien no cumple a cabalidad con nuestras nociones de una buena traducción [...] de modo general, el sr. Irvine ha tenido éxito con el diálogo, que se encuentra escrito en verso blanco: este segmento de su versión resulta siempre vigoroso $\mathrm{y}$, a menudo, muy poético (Moir, 1837, pp. 246-247). ${ }^{14}$

Por lo tanto, desde su posición de catedrático en la Universidad de Edimburgo, Moir se constituiría en una autoridad de crítica literaria, en el oficio de la traducción y en la literatura castellana y alemana.

\section{E1 modelo de reseñas británico y el periodismo de Andrés Bello en El Araucano}

Otro aspecto que llama la atención es la confluencia temática, durante la década de los

14 'We regard Mr. Irvine's translation of this poem as a highly creditable and, on the whole, successful attempt to convey to the English reader an idea of this choral drama. Not that it by any means satisfies our notions of a good translation [...] Generally speaking, Mr. Irvine has been most successful in the dialogue which is in blank verse: this portion of his version is always vigorous, and often highly poetical". veinte del siglo XIX, entre George Moir y Andrés Bello, dado que compartían el interés en el estudio de la antigua literatura española y su afición a la lectura de The Edinburgh Review. Esto, teniendo en cuenta las investigaciones realizadas por Bello sobre poesía medieval y romances españoles en la biblioteca del Museo Británico de Londres (Lovera De Sola, 1981).

Es probable que el intelectual venezolano haya leído alguna reseña de Moir (sin saber su autoría, debido a que estos artículos se publicaban sin firma) sobre obras de poesía castellana. Por ejemplo, ambos reseñaron la colección de romances españoles antiguos publicada por Georges Bernhard Depping. Moir reseñaría la publicación original en alemán de 1817 en su artículo "Early Narrative and Lyrical Poetry of Spain", impreso en The Edinburgh Review en 1824, mientras que Bello esperó a que se publicara la traducción española de esta colección para reseñarla en un breve comentario bibliográfico que se incluyó en El Repertorio Americano en 1826 (Bello, citado en Grases, 1973, pp. 319320). Al revisar la reseña de Bello, queda patente que estudió y cotejó la recopilación original de 1817 y la traducción española de $1825 .^{15}$

El hecho de que algunos hispanoamericanos se encontraban desterrados en Londres, durante las primeras décadas del siglo XIX, dados los acontecimientos de las independencias americanas, despertó interés en los círculos liberales. Esta atención por la causa hispanoamericana fue retratada en revistas literarias y científicas como The Edinburgh Review (Shattock, 1989). Esto suscitó que varios exiliados americanos

15 Bello escribiría, sobre la colección de Depping traducida al español, que: "El editor de esta colección la ha reducido a 224 romances de la clase anunciada en el título, omitiendo los restantes hasta el número de 300 publicados por Depping el año 1817 en Leipsick [...]. Los romances históricos comprendidos en esta edición ofrecen la inestimable ventaja de poderse leer en letra clara y texto correcto y limpio" (Bello, citado en Grases, 1973, p. 319). 
hayan sido lectores de la revista. Por lo tanto, eso podría explicar que las publicaciones británicas desempeñaran un rol relevante como modelo en la práctica periodística de Andrés Bello en $E l$ Araucano.

Si bien esta revista publicaba exclusivamente reseñas de libros, cuyo formato se encontraba delimitado -artículos encabezados por el o los títulos de los libros reseñados, y publicados sin firma-, eso no impedía que la reseña con frecuencia ofreciera "un espacio completo a las opiniones y reflexiones del mismo reseñador" (Alberich, 1980, p. 127). Según José Alberich, la reseña no solo se centraba en comentar una obra determinada, sino que se convertía en "un espacio libre para que el reseñador se transformara en un ensayista" (1980, p. 128). Por lo tanto, no es de extrañar que la propagación de las críticas de las publicaciones literarias se entrelazara con el éxito en el tiraje de las publicaciones de revistas de reseñas durante la época, como era el caso de The Edinburgh Review. Las palabras de Thomas Carlyle, en una reseña publicada en diciembre de 1831, explicitan la sensación que incluso podía percibirse fuera de Gran Bretaña:

Acaso no quedaría en evidencia el trastornado estado autoconsciente de la literatura mediante este único hecho, que se encuentra tan cercano a nosotros: La prevalencia de la Reseña [...] La escritura de reseñas se extiende con peculiar vigor, tanto que un hombre como Byron considera iguales al reseñador y al poeta [...]. Tarde o temprano se descubrirá que toda la Literatura se ha transformado en una infinita Reseña que se devora a sí misma (Carlyle, 1831, pp. 369-370). ${ }^{16}$

16 "Nay, is not the diseased self-conscious state of Literature disclosed in this one fact, which lies so near us here, the prevalence of Reviewing [...] Reviewing spreads with strange vigour; that such a man as Byron reckons the Reviewer and the Poet equal [...]. By and by it will be found that all Literature has become one boundless self-devouring Review".
Es altamente probable que Bello, lector de esta revista desde sus años de exilio en Londres, haya sido conocedor de este enfoque de redacción para periódicos y aficionado a él, lo cual explicaría la llegada habitual de textos provenientes de aquella a las columnas de El Araucano.

Este vínculo de larga data entre Bello y esta publicación inglesa sería otra posible razón para atribuirle al intelectual venezolano la autoría, como traductor y editor, de este texto sobre traductología publicado en El Araucano.

Ya un contemporáneo de Bello, durante el periodo de su llegada a Chile, a fines de la década de los veinte, el escritor español José Joaquín de Mora, expresaría, en un artículo publicado en 1827 en el periódico Crónica Política y Literaria de Buenos Aires, que

[...] lo que un modesto periodista confía al papel en Edimburgo, se transmite como chispa eléctrica a las orillas del Ganges y de la Plata, al pie de los Alpes y de los Andes (Mora, 1827, citado en Rodríguez Monegal, 1969, pp. 159-160).

Con estas palabras, autores como José Joaquín de Mora, y también Andrés Bello, evidenciarían su percepción del rol que desempañan las publicaciones británicas en el traslado de ideas a diversas regiones, pero que, esta vez, cruzarían hasta el cono sur americano.

Es conocido el papel que cumplió Bello, desde 1831 hasta 1850, como divulgador del periodismo y la crítica literaria en la redacción de la sección literaria y científica de El Araucano (Álvarez, 1981; Amunátegui, 1901; Bulnes, 1953; Fontaine, 1982; Jaksic, 2004; Martínez Baeza, 2014; Silva Castro, 1958). Raúl Silva Castro señala que, en los ejemplares de El Araucano, existía una "parte exterior, en la que se ofrecían regularmente traducciones de diarios extranjeros [...] que entonces ningún periódico chileno podía jactarse de poseer" (1965, p. 59). Además, Silva Castro destaca que Bello, en El Araucano,

[...] fue siempre el especialista de esta parte exterior, sin perjuicio, además, de correr con el 
arreglo de todo lo que se publicaba, a modo de secretario de la redacción, como se diría en el lenguaje moderno de los diarios (1965, p. 59).

Según Alfonso Bulnes, la obra periodística de Be110 "fundaría en Chile durante la década de 1830, de modo sistemático, dos secciones de periodismo palpitante"; estos serían "la crítica literaria de la producción reciente" y "la crítica de los espectáculos teatrales" (1953, p. 146).

Por medio de sus traducciones de artículos extranjeros o de colaboraciones originales, Bello orientó el gusto literario de los lectores del periódico. Además, a través de la publicación de sus comentarios desde la redacción de El Araucano, mantuvo constantes pugnas con la censura de libros y manifestó su afán de posicionarse a favor de una difusión crítica del teatro en Chile (Botta, 2015). Simultáneamente, introdujo, de manera gradual, las "nociones de la nueva escuela romántica", con las obras que se estrenaban en Chile (Rodríguez Monegal, 1969, p. 184).

Bello, en las páginas de El Araucano, ejercía un rol de comentador y reseñador a través de numerosos artículos extractados y traducidos de revistas y periódicos europeos y estadounidenses. ${ }^{17}$ Naturalmente, este fenómeno no atañe de manera exclusiva a Chile, por cierto; otros estudios han destacado el rol de la prensa francesa en el campo literario brasileño, principalmente en los periódicos de Río de Janeiro durante el siglo XIX (Ramicelli, 2009). En este caso, quedaría patente el afán "utilitario" de la traducción en las decisiones y estrategias editoriales del periódico. Por ejemplo, en un comentario publicado el 12 de diciembre de 1834 en El Araucano, al comentar un tratado francés de geografía, del militar

17 Se pueden destacar extractos de periódicos franceses como Le Globe y Journal des Débats, y de publicaciones norteamericanas como American Quarterly Review. Sin embargo, existe una preferencia por traducir artículos de periódicos británicos. francés Maxime Auguste Denaix (1777-1844), Bello señalaría que

[...] nos parece seria de la mayor utilidad en este país para el uso de los establecimientos de educación, traduciéndose el texto y los cuadres, que tienen la ventaja de ser sumamente comprensivos (1834, p. 3).

Más adelante, otra sección de este texto establece que

Es ya tiempo de que volvamos los ojos a lo que se adelanta en otras partes, y de que nos apropiemos, en cuanto sea posible, de las inmensas adquisiciones que hace cada día la actividad intelectual de las naciones europeas (Bello, 1834, p. 3).

Es evidente el llamado a la apropiación por parte de Bello, un modo de recopilar textos "útiles", dispuestos a ser manipulados por el traductor y el redactor, para así suplir los espacios disponibles en las columnas de El Araucano. Encontramos un ejemplo de esto en el año 1833 , cuando se publicaría una breve traducción de extractos de una reseña (atribuida a George Moir) de obras teatrales francesas del dramaturgo francés Eugene Scribe, publicada en mayo de 1832 en The Foreign Quarterly Review, con el título de "Minor French Theatre" (Houghton et al., 1989, p. 548). El texto podría considerarse uno de los primeros artículos de "crítica teatral moderna" publicados en Chile durante el siglo XIX. ${ }^{18}$

18 La reseña consistía en un comentario de cuatro obras: la primera era una compilación de obras dramáticas de Eugène Scribe dedicada a sus colaboradores, cuyos ocho volúmenes fueron publicados en París entre 1828 y 1830; la segunda era la obra La Vengeance d'une Italienne, de Eugène Scribe, Gaspard Delestre y Charles Desnoyers; la tercera comprendía la ópera Robert le Diable, de Eugène Scribe y Germain Delavigne, y, finalmente, la ópera cómica La Marquise de Brinvilliers, de Eugène Scribe y compañía, de 1831 (Moir, 1832, p. 447). La traducción de la reseña lleva el título "Eujenio Scribe" (Bello, 1833, p. 4). 
Es posible que Bello publicara la traducción de este juicio teatral de Moir por la necesidad de contar, a la mayor brevedad posible, con una reseña teatral que informara alguna opinión experta sobre el dramaturgo francés, cuya obra fue estrenada durante el mes de noviembre de 1833 en un teatro de la ciudad de Santiago de Chile. Bello presentó la reseña, días después, con este breve comentario introductorio, en $E l$

\section{Araucano:}

El martes pasado se representó en nuestro teatro el Felipe ó la Madre incógnita, pieza del célebre Scribe. Los papeles estuvieron todos mui bien distribuidos y se ejecutaron a satisfacción de los espectadores [...]. Eujenio Scribe, el autor de la pieza, es incontestablemente el primero de los escritores dramáticos de nuestros días. Esperamos que no será desagradable a nuestros lectores ver el juicio que se hace de este hombre singular en la Revista Estranjera de Lóndres (Foreign Quarterly Review) n. XVIII (Bello, 1833, p. 4).

Fue el estreno el que ameritaba publicar un material "útil" en la prensa, que estuviese vinculado con la contingencia del escenario teatral del momento en Santiago de Chile. La práctica de la traducción cumplía el rol de ayudar a suplir de textos que no se encontraban en Chile, en un plazo inmediato. Como expresa Gertrudis Payàs, "la traducción, como fenómeno cultural, es la medida del deseo del libro ajeno" (2007, p. 37). Por lo tanto, en el traducir existe un afán de adquirir lo que no se tiene.

A continuación se presenta, brevemente, el contexto de producción, principalmente las circunstancias en el plano literario, del año 1838, en el que Bello tradujo la obra Teresa, de Alexandre Dumas, proceso que acompañó la escritura y publicación del texto "Sobre las traducciones".

\section{El contexto de producción del texto "Sobre las traducciones", de Andrés Bello}

Desde 1835, año en que se produce el retiro del abogado e impresor chileno Manuel José
Gandarillas (1789-1846) de la redacción de $E l$ Araucano, tarea que cumplía desde su fundación en 1830 (Bulnes, 1934, p. 68), Bello toma el control total de la redacción de las noticias extranjeras y de la sección literaria del periódico (Briseño, 1862, pp. 26-27; Martínez Baeza, 2014, p. 106).

En 1836, el político y poeta chileno Salvador Sanfuentes (1817-1860) se incorporaría parcialmente a la redacción del periódico, colaborando con Bello hasta 1839. Sanfuentes publicaría, en el periódico, algunos artículos sobre la guerra librada por Chile contra la Confederación Perú-boliviana, principalmente entre los años 1836 y 1839 (Arteaga Alemparte, 1860, p. 565). Este panorama dejaría dos posibles autores de la traducción del texto de Moir: Andrés Bello y Salvador Sanfuentes. Sin embargo, la opción de atribuirla a Sanfuentes pierde fuerza si consideramos el elevado nivel de inglés empleado por el traductor. Sanfuentes tenía 21 años a la fecha de la traducción y no existen antecedentes de que manejara un nivel aceptable de esa lengua en esa época. Él solo había publicado en 1834, en el mismo periódico y con el aliento de Bello, una traducción desde el francés de un fragmento de la "Ifigenia en Aulide", del dramaturgo Jean Racine (1639-1699) (Racine, 1834, p. 3). Bello, además, tenía completo dominio de la sección literaria. Del mismo modo, se vislumbra su participación como editor en la elección del periódico extranjero (The Edinburgh Review) y del tema de la reseña (traducciones), aspectos, ambos, que constituían objeto de interés para Bello. Por último, en este caso resulta clave la tarea que había emprendido Bello en 1837, en la traducción de la obra Teresa, del dramaturgo francés Alexandre Dumas (1802-1870).

En septiembre de 1837, se insertó en El Araucano un aviso publicitario que señalaba:

\footnotetext{
Habiéndose solicitado con instancia por varias personas inteligentes la impresión de la "Teresa", tragedia del célebre Dumas, traducida al castellano por un aficionado, y representada
} 
con el mayor aplauso en el teatro de esta capital; el traductor, cediendo al voto respetable de aquellos señores, ha determinado abrir una suscripción para darla a la prensa. Se imprimirá en buen papel y letra, y con la debida corrección: de la que carecen todas las copias manuscritas que existen en esta República y fuera de ella. Se venderá cada ejemplar a 6 reales. Los señores que deseen suscribirse se servirán hacerlo en la "Imprenta de la Opinión" (Bello, 1837, p. 4).

Este aviso resulta ilustrativo para señalar que, durante el periodo que comprenden los años de 1837 y 1838 , la traducción tomó un rol central en el panorama literario del periódico. Es posible considerar que Bello haya sido el responsable del acercamiento temático de El Araucano hacia la traducción, con la intención de fomentar la reflexión sobre el oficio o la práctica de este entre sus lectores.

Rodríguez Monegal añade que la traducción de Teresa, realizada por "un aficionado", se puede atribuir a Bello y que el periódico chileno, bajo la pluma y la edición de aquel, tomó en cierta forma los ribetes de un "curso de literatura, principalmente contemporánea" (1969, p. 207). Por supuesto, el texto "Sobre las traducciones", de 1838, también se puede situar dentro de este programa de formación literaria fomentado por Bello, con el objetivo de plantear la traducción literaria como un tema relevante en la prensa chilena del periodo.

\section{Análisis y cotejo de la traducción de Bello y el texto original}

A continuación se coteja la traducción de Bello, publicada en la edición del 10 de agosto de 1838 de El Araucano (Bello, 1838), y el texto fuente, publicado como la décima reseña (a una traducción inglesa realizada por George Irvine de la tragedia "La novia de Messina", de Friedrich Schiller) de la edición del mes de julio de 1837 de The Edinburgh Review (Moir, 1837).

Bello, primeroquetodo, cambiaeltítulodeltexto, renombrándolo como "Sobre las traducciones" y añade enseguida "Del Edinburgh Review". Suprime toda referencia editorial a la obra reseñada en el original. Bello traduciría solo extractos que comprenden la primera mitad de la reseña, principalmente el contenido que está entre la página 239 y el primer párrafo de la página 244 , suprimiendo todo el contenido de las páginas 244 a 251.

El texto que resultó de la traducción incorporó referencias de cuatro traductores europeos, tres británicos: John Dryden, ${ }^{19}$ Edward Fairfax ${ }^{20}$ y Alexander Pope, ${ }^{21}$ y un alemán: August Wilhelm Schlegel, ${ }^{22}$ que fueron usados como ejemplo por Moir para la introducción de su reseña. Sin embargo, en la traducción de Bello se nota un

19 John Dryden (1631-1700) fue un escritor, poeta inglés, célebre en su época por su traducción de La Eneida, publicada en 1697 (Hammond, 1991). También es una figura relevante en los estudios de traducción por categorizar a la traducción en tres grandes prácticas: la "metafrase" (una traducción literal), la "parafrase" (definida como traducción con libertad) y la "imitación” (Munday, 2016, p. 43).

20 Edward Fairfax (1580-1635) fue un traductor inglés, célebre por publicar en 1600 su traducción al inglés de La liberación de Jerusalén del poeta italiano Torquato Tasso. Miguel Luis Amunátegui explica que encontró a Bello comenzando la traducción de algunos versos de este poema: "Se había puesto a traducir la Jerusalén Libertada de Torcuato Tasso; pero tardó en descontentarse sobremanera de este trabajo, que, llevado a término, habría sido para él un nuevo lauro literario" (Amunátegui, 1883, p. cxxix).

21 Alexander Pope (1688-1744) fue un dramaturgo y poeta inglés, traductor de los poemas homéricos La Ilíada (publicada entre 1715 y 1720) y La Odisea (entre 1725 y 1726) (Rogers, 2007, pp. XIII-XVII).

22 August Wilhelm Schlegel (1767-1845) fue un poeta y dramaturgo alemán. Figura significativa, junto con su esposa Caroline, en el desarrollo del romanticismo de Jena (Behler, 1993, pp. 14-23). Se desempeñó como profesor de sánscrito y editó entre 1823 y 1830 la Indischen Bibliothek (Biblioteca hindú), compuesta por traducciones al alemán del texto sagrado Bhagavad Gita (1823) y el texto épico Ramayana (1829), entre otros (Bhatti, 2010, pp. 241-250). Reconocido por ser un divulgador y traductor de las obras de Shakespeare en lengua alemana (Atkinson, 1958). 
mayor acercamiento a la obra de Dryden, Pope y Schlegel. Bello, de esta manera, incorporó el contenido y la reflexión ensayística propia del estilo de la reseña de Moir, para ofrecer en el periódico chileno un contenido inmediato y a su vez panorámico sobre la traducción literaria en Europa de los siglos XVII y XVIII.

Lo primero que destaca en el Ejemplo 1 es que Bello simplifica el contenido y también suprime la referencia a lo "inglés" presente en el texto de Moir: Bello traduce "to communicate on the whole to the mere English reader" por la frase "que ofrezca al lector", y el final de la pregunta

Ejemplo 1

Pero la cuestión es żcómo podemos llegar o acercarnos más a este grado de perfección? ¿por qué sistema de traducción ha de efectuarse esta alianza de lo extranjero y lo doméstico, de manera que ofrezca al lector que no puede entender el original al trasunto más fiel de las gracias clásicas de la antigüedad, del brillante y pomposo orientalismo de la poesía castellana, de la serena transparencia de la italiana, o del pensativo y caviloso espíritu de la germánica, o que haga percibir y distinguir en el vehículo de nuestra lengua nativa la concisa grandeza del Dante, el tono tierno, devoto y lirico del Taso, la lozana fantasía y remontado entusiasmo de Calderón?

Fuente: Bello (1838, p. 1).

emprenderla en Chile. Es decir, la reflexión se traslada y se aplica para Chile, y no se queda solo en una discusión exclusivamente europea.

El traductor también introduce algunas pequeñas modificaciones por medio de la elección de términos; por ejemplo, la expresión "the truest idea of the classic graces of antiquity" queda traducida como "al trasunto más fiel de las gracias clásicas de la antigüedad". planteada en el original como "in the common vehicle of English", por "en el vehículo de nuestra lengua nativa" (el énfasis es mío).

Es altamente probable que el gesto de Bello, al traducir de esta forma, sea generalizador, en el sentido de que sea un vehículo identificable para cualquier grupo — sin importar la lengua - que decida reflexionar sobre el problema de la traducción. Por lo tanto, se transportaría una problemática de la crítica literaria británica sobre textos de otras regiones europeas, como un punto de partida para la reflexión sobre la traducción literaria, como impulso para
But the question is, how is this perfection to be attained, or approached more nearly? By what system of translation is this union of the foreign and domestic to be effected, so as to communicate on the whole to the mere English reader the truest idea of the classic graces of antiquity, the glowing Orientalism of Spanish poetry, the sunny clearness of the Italian, or the pensive and brooding spirit of the German? -or to render the succinct grandeur of Dante, the tender, devoted, and lyric tone of Tasso, the exuberant fancy and soaring enthusiasm of Calderon, all perceptible and distinguishable in the common vehicle of English?

Fuente: Moir (1837, p. 239).

En las breves descripciones dadas por Moir de la poesía en lengua castellana, italiana y alemana, Bello también nutre su traducción con pequeñas transformaciones. Respecto a la poesía castellana (Bello decide usar esa voz, en vez de "española"), se traduce "glowing Orientalism" por "pomposo orientalismo". Sobre la poesía italiana: "sunny clearness", por "serena transparencia". En el caso de la poesía en lengua

\section{Ejemplo 2}

Toda versión es una especie de compromiso. La animación y la fidelidad literal serian apenas conciliables traduciendo en prosa: cuando el traductor tiene que luchar con los embarazos del verso, y todavía más cuando trata de copiar el ritmo y cadencia métrica del original, esta conciliación es, por descontado imposible.

Fuente: Bello (1838, p. 1).
All translation is of course a compromise. To be perfectly
literal, and perfectly spirited, would be scarcely
practicable in a prose translation; in one where the
translator has to encounter the additional trammels of
verse, and still more where an attempt is made to copy
the rhythm and metrical cadence of the original, it is of
course impossible.
Fuente: Moir (1837, p. 239). 
alemana: "the pensive and brooding spirit", por "pensativo y caviloso espíritu".

En el Ejemplo 2 se encuentra una de las decisiones más interesantes que toma Bello. En su traducción, este traduce la frase "All translation is of course a compromise" por "Toda versión es una especie de compromiso". Bello escoge el vocablo "versión" para traducir "translation" (traducción), estableciendo una sutil transformación del texto.

\section{Ejemplo 3}

Entre nosotros la opinion general y la práctica han estado constantemente a favor de las traducciones arregladas a este plan de moderada libertad. En nuestras primeras versiones de escritores clásicos y extranjeros se adoptó ciertamente, o a lo ménos se proclamó, el principio de la fidelidad literal; y en este jénero la traducción de la Jerusalen, por Fairfax, fue una obra maestra. Pero el gran talento de Dryden* produjo una revolución en este punto.
In England, the prevailing practice and opinion has long been in favour of the liberal system of translation. Our early versions of classic and foreign writers were no doubt framed, professedly at least, on the principle of literal translation; and in this style Fairfax's translation of the Jerusalem was a masterpiece. But a revolution was effected in English translation by the great talent of Dryden.

* Bello inserta en su traducción una nota al pie con la mención "Traductor de la Eneida".

Fuente: Bello (1838, p. 1). Fuente: Moir (1837, p. 240).

En el Ejemplo 3 de nuevo se encuentra, en la traducción de Bello, el gesto de suprimir la referencia literal a Inglaterra, traduciendo "In England" por "Entre nosotros". Posteriormente, traduce la expresión "the liberal system of translation" por "las traducciones arregladas a este plan de moderada libertad".

En este Ejemplo 3 llama la atención la elección del término "fidelidad literal" para traducir " $i j-$ teral translation".

Por cierto, Bello introduce, para los lectores, una nota al pie, haciendo una breve referencia a John Dryden y su traducción inglesa de $L a$ Eneida, de Virgilio. El texto de Moir publicado en The Edinburgh Review no contaba con notas a pie de página. El mismo uso de notas por parte de Bello también hace referencia al poeta inglés Alexander Pope y su traducción de las obras homéricas La Ilíada, publicada entre 1715 y 1720, y La Odisea, en 1725.

En el Ejemplo 4, Bello suprime el final del párrafo. No incluye en la traducción la referencia latina de Dryden "Vertitur interea coelum et ruit oceano nox" ni la respectiva traducción al inglés hecha por Moir;

\section{Ejemplo 4}

Pero su misma fértil inventiva le incapacitaba de consagrar a sus composiciones de esta clase todo aquel prolijo cuidado que es necesario para trasladar con precisión los conceptos ajenos, en palabras que siendo castizas e idiomáticas, sean al mismo tiempo fieles y literales; en una palabra, para hacer traducciones verdaderas, no parafráticas. No hai duda que algunas veces hasta mejora lo que traduce.
But the very fertility and originality of his own mind rendered it difficult for him to devote to his compositions of this kind that patient attention which is required to convey the exact meaning of the original, in words at once idiomatically English, and yet close and literal; -to make his versions, in short, properly translations, as distinguished from paraphrases.

Undoubtedly at times he may even improve upon his original, as in his noble version of the line 'Vertitur interea coelum et ruit oceano nox.'

'Mean-time the rapid heavens rolled down the light, And on the shaded ocean rushed the night.'

Fuente: Moir (1837, p. 240). 
tampoco traduce la frase al español. Traduce los dos términos "fertility and originality" como un sustantivo ("inventiva") acompañado de un adjetivo, quedando como "fértil inventiva". Traduce la expresión "patient attention" como "prolijo cuidado"; posteriormente, "to convey the exact meaning of the original", Bello lo traduce como "trasladar con precisión los conceptos ajenos".

Claramente, en este Ejemplo 4 no se está ante una traducción literal: Bello traslada el sentido de las frases; sin embargo, introduce modificaciones que las alteran, principalmente por la sustitución de "the original" por el pluralizado "conceptos ajenos". Bello remata la traducción del párrafo mediante la supresión de la alusión a las palabras inglesas y reemplazándolas por "palabras castizas". Existe una pluralidad de interesantes elecciones de Bello que quedan en evidencia: "close and literal" traducido como "fieles y literales" y, al final, "even improve upon his original" por "hasta mejora lo que traduce".

Por cierto, la germanofilia de Moir es evidente, y se explica dada su cercanía con los autores alemanes, desde sus conversaciones con su maestro William Hamilton en Edimburgo en la década de los veinte. Sin embargo, Bello probablemente no considera el modelo alemán de traducción, ca-

\begin{abstract}
Ejemplo 5
La regla de los mas eminentes traductores alemanes ha sido hundirse enteramente en el orijinal; mirarse como meros intérpretes de los conceptos de un extranjero en la lengua jermánica; abstenerse de añadir o suprimir cosa alguna; no emplear la paráfrasis, donde quiera que pueda traducirse literalmente sin oscuridad ni violencia; copiar, no sólo las ideas, sino, en cuanto cabe, el movimiento de la versificación, el órden de las rimas, y las cadencias del orijinal.
\end{abstract}

Fuente: Bello (1838, p. 1).

racterizado por poseer una literalidad y fidelidad excesiva al original, como la forma adecuada de traducir (véase Ejemplo 5).

Es muy posible que el desencuentro teórico, en el plano de la discusión sobre el método adecuado, llega a tal punto que Bello incluso suprime la mención de Moir, lo que causa una alteración en el sentido del texto. Dado esto, se visibiliza el gesto irónico de Bello; al traducir, establece una libertad de manipular el texto fuente: suprimir secciones, modificar topónimos, cambiar el título, obviar las referencias, entre otras estrategias editoriales. Por lo tanto, los propósitos de George Moir de enaltecer una forma adecuada de traducir, bajo los principios de mantener la literalidad, resultan ignorados en las elecciones del traductor.
The principle of every German translator of any eminence has long been, to sink himself entirely in his original; to look upon himself as the mere sworn interpreter of a foreigner's meaning, in his own language; to permit himself no liberties either of addition or retrenchment; never to use a mere paraphrase, where without violence or obscurity the meaning of the original can be literally rendered; and to copy not merely the meaning of the passage translated, but, as far as possible, the movement of the versification, the arrangement of the rhymes, the fall of the cadences of the original.

Fuente: Moir (1837, p. 242).

Es a través del cotejo, entre el texto fuente y el texto traducido, que se pueden visibilizar estos sutiles gestos de Bello, particularmente interesantes por la fina ironía que se plasma en ellos. Como en la ya mencionada negociación de Venuti (2000, p. 468), si bien Bello acepta o acata el contenido del texto fuente hay un número importante de ajustes y modificaciones que contradicen el contenido de lo que se traduce, principalmente influenciado por "intereses domésticos".

A Bello le resulta imposible tomar al pie de la letra las ideas planteadas por Moir, principalmente por el contexto histórico-cultural en que se insertaba esta traducción en Hispanoamérica: el formato del periódico, los intereses 
Los defectos de las traducciones alemanas son casi siempre tirantez y aspereza, dimanados de una fidelidad excesivamente escrupulosa; pero nadie que no esté iniciado en la literatura alemana puede figurarse hasta qué punto son fieles; y al mismo tiempo animadas y vigorosas las que se han hecho de escritores ingleses y continentales.

Fuente: Bello (1838, p. 1).

del traductor y los de los lectores, entre otros aspectos.

En el Ejemplo 6 se produce un distanciamiento entre el autor y el traductor. Bello realiza una modificación importante del texto fuente; primero traduce la mención de Moir sobre la traducción de los alemanes "from too close an adherence to the originals" por "una fidelidad excesivamente escrupulosa". Además, Bello suprime el pasaje "the least idea of the perfection" ("tener la menor idea de la perfección") al referirse Moir en su texto a la perfecta ejecución de las versiones alemanas.

No es la primera vez que Bello destacaría la "fidelidad escrupulosa" como característica de una forma de traducir. En 1816, estando en Londres, Bello se encargaría, por razones de necesidad económica, de corregir una traducción española de la Biblia. Fue a raíz de este trabajo que el escritor venezolano reflexionaría sobre "el modo de verterla a los idiomas modernos" (Amunátegui, 1882, p. 146). Respecto al estilo y la forma de traducir textos religiosos, Bello señalaría:

Una fidelidad escrupulosa es el primero de los deberes del traductor; i su observancia es mas necesaria en una traducción de la Biblia, que en otra cualquiera. El que se propone verterla, no solo está obligado a trasladar los pensamientos del orijinal, sino a presentarlos vestidos de las mismas imájenes, i a conservar, en cuanto fuere posible, la encantadora naturalidad, la injenua sencillez, que dan una fisonomía tan característica a nuestros libros sagrados. Lo que en otras obras pasaría por desaliño, puede
The defects of German translations are almost always on the side of ruggedness or stiffness, from too close an adherence to the originals; but no one who has not some acquaintance with German literature can form the least idea of the perfection - both in point of fidelity, and of spirit and freedom, with which some of the German versions, both from our own writers, and from those of the Continent, have been executed.

Fuente: Moir (1837, p. 242).

ser la verdadera elegancia en una versión de la Biblia (citado en Amunátegui, 1882, p. 147).

Bello concluiría, en esa ocasión, que el estilo de una traducción depende del género literario en que estaba inscrito el texto fuente. No se pueden establecer las mismas reglas para la poesía que para los textos sagrados. Así, esta regla de "fidelidad escrupulosa" en Bello, al parecer, tendría límites, de acuerdo con el género del texto que se traduce.

La relevancia de la "fidelidad escrupulosa" también aparece en la crítica a la traducción de José Gómez Hermosilla de La Ilíada de Homero. Bello expresa que la pretensión de fidelidad del traductor condiciona la posterior evaluación de la traducción:

Ni notaríamos esta especia de faltas, si él mismo no anunciase, en su prólogo, que su versión está hecha con la más escrupulosa fidelidad. Es verdad que rectifica este anuncio, previniendo que se ha tomado la licencia de suprimir epítetos de pura fórmula, o notoriamente ociosos, y de añadir algunos que le parecieron necesarios. Pero esto es cabalmente de lo que debía haberse abstenido un traductor que se precia de escrupuloso (Bello, 1981, p. 420).

Finalmente, habría modos de traducir, que Bello identifica con las traducciones alemanas, donde se sobrepasan las fronteras de una "fidelidad adecuada" por excesos de estilo que perjudican a las traducciones con "tirantez" y "asperezas".

Bello, en su traducción, no traslada a su texto que la ejecución de estas traducciones germanas 
sea "perfecta"; al contrario, lo traduce como "puede figurarse hasta qué punto son". Bello traslada las características correspondientes a ellas como, por ejemplo, "fidelity" por "fieles", "of spirit" por "animadas", y "freedom" por el término "vigorosas". Se puede deducir, a partir de las elecciones de Bello al traducir, que existe una resistencia a las ideas de Moir respecto a los traductores alemanes.

\section{Comentarios finales}

Existe una interesante contradicción que queda patente entre el contenido, la teoría de lo que se traduce y la práctica de la traducción. Lo peculiar de este caso es que, gracias a la posibilidad de contar con el texto fuente y haber identificado a su autor, es factible hacer el ejercicio de cotejar y construir un diálogo hipotético entre dos contextos distintos, todo sobre un mismo texto.

Si bien el texto fuente, la reseña de Moir, mantiene una posición firme y prescriptiva sobre la forma "adecuada" de traducir, Bello, en un gesto quizás irónico o hasta burlesco, condicionado por las circunstancias del contexto en que la traducción se inscribe, interpela de manera indirecta, por medio de su traducción, el contenido sobre la forma adecuada de traducir. Se trata de un gesto muy peculiar e interesante de Bello, que se visibiliza al cotejar los textos.

De nuevo, recurriendo a la figura de Juan Poblete, el "lector latinoamericano" deviene crítico y autor, a través de la traducción. Bello indirectamente critica algunas de las ideas del texto de Moir por medio de la selección y de la forma en que traduce la reseña del autor escocés. Sin embargo, esta idea solo emerge a través del cotejo, que permite visualizar e identificar las discrepancias, las diferencias y las continuidades entre el texto fuente y la traducción.

La elección de Bello se vincula con lo que señala la investigadora María Alejandra Valero con relación a que, en la época, existía entre los escritores latinoamericanos un movimiento de imitaciones de modelos literarios. De este modo, según Valero, el imitar "no implicaba traducir, sino crear", ya que "el propósito de la imitación no era la fidelidad con respecto al original sino más bien usarlo de modelo para la producción de una nueva obra" (2013, p. 46). Es decir, no se necesitaban "traducciones", sino "versiones". Por lo tanto, el contenido íntegro que se vertía en el texto "Sobre las traducciones" implicaba la defensa de una práctica de la traducción que se rigiera por la fidelidad, una "fidelidad escrupulosa" en palabras de Bello, el rechazo de prácticas que añadieran, modificaran o suprimieran partes del texto. Sin embargo, el cotejo de la traducción con el texto original evidencia una metodología de añadiduras, paráfrasis y supresiones de pasajes.

La publicación de esta traducción marca la importancia que tiene la prensa periódica en brindar un panorama "a tiempo real" de la adquisición de temas, ideas y reflexiones de los periódicos foráneos. Se espera que este artículo permita, en el futuro cercano, el desarrollo de más estudios sobre estas fuentes.

\section{Referencias}

Alberich, J. (1980). Actitudes inglesas ante el mundo hispánico en la época de Bello. En O. Sambrano Urdaneta (Ed.), Bello y Londres. Segundo Congreso del Bicentenario (Tomo I, pp. 125-164). Fundación La Casa de Bello.

Álvarez, F. (1981). El periodista Andrés Bello. La Casa de Bello.

Amunátegui, M. L. (1882). Vida de don Andrés Bello. Imprenta Pedro G. Ramírez.

Amunátegui, M. L. (1883). Introducción. En Obras completas de don Andrés Bello (Volumen VI, pp. v-cxlii). Imprenta Pedro G. Ramírez.

Amunátegui, M. L. (1901). Don Andrés Bello en el periodismo. Anales de la Universidad de Chile, (109), 673-804. https://doi:10.5354/07178883.2012.21817

Arroyave, A. (2013). Georges Bastin y la Historia de la traducción en América Latina. Mutatis Mutandis. 
Revista Latinoamericana de Traducción, 6(1), 275278. https://revistas.udea.edu.co/index.php/ mutatismutandis/article/view/15312

Arteaga Alemparte, D. (1860). Estudio sobre la vida i escritos de Don Salvador Sanfuentes. Revista del Pacífico. Publicación literaria i científica, (3), 559-575.

Atkinson, M. E. (1958). August Wilhelm Schlegel as a translator of Shakespeare. A comparison of three plays with the original. Basil Blackwell.

Barros Arana, D. (1902). Historia Jeneral de Chile (Vol. XVI). Imprenta Cervantes.

Bassnett, S. y Trivedi, H. (1999). Introduction: Of colonies, cannibals and vernaculars. En S. Bassnett y H. Trivedi (Eds.), Post-colonial translation. Theory and practice (pp. 1-18). Routledge.

Bastin, G. L, Echeverri, A y Campo, A. (2004). La traducción en América Latina: propia y apropiada. Estudios. Revista de Investigaciones Literarias y Culturales, (24), 69-94.

Behler, E. (1993). German romantic literary theory. Cambridge University Press.

Bello, A. (1833, noviembre 29). Eujenio Scribe. El Araucano, (168), 4.

Bello, A. (1834, diciembre 12). Editorial. El Araucano, (222), 3.

Bello, A. (1837, septiembre 15). Teresa, de Alejandro Dumas. El Araucano, (368), 4.

Bello, A. (1838, agosto 10). Sobre las traducciones (Del Edinburgh Review). El Araucano, (415), 1.

Bello, A. (1981). La Ilíada. Traducida por don José Gómez Hermosilla. En Obras completas de Andrés Bello (Temas de crítica literaria Vol. IX, 417-427). La Casa de Bello.

Bhatti, A. (2010). August Wilhelm Schlegels Indienexperiment. Kulturtransfer und Wissenschaft. En Y.-G. Mix y J. Strobel (Hrsg.), Der Europäer A. W. Schlegel. Romantischer Kulturtransfer - Romantischer Wissenswelten (pp. 237253). De Gruyter.

Botta, M. (2015). Andrés Bello y su labor como crítico teatral en Chile. Romance Notes, 55(1), 3541. https://doi.org/10.1353/rmc.2015.0007

Briseño, R. (1862). Estadística bibliográfica de la literatura chilena. Obra compuesta, en virtud de encargo especial del consejo de la Universidad de Chile. Imprenta Chilena.

Bulnes, A. (1934). La prensa chilena en la época de Portales. Anales de la Universidad de Chile, (16), 52-73. https://doi:10.5354/07178883.2013 .26763

Bulnes, A. (1953). Don Andrés Bello y el periodismo. Boletín de la Academia chilena de la Historia, (48), 137-149.

Carlyle, T. (1831). Characteristics. The Edinburgh Review, 54, 351-383.

Domínguez, M. C. (2018). La traducción literaria, "un laboratorio de escritura": revistas culturales, género y plurilingüismo. Entrevista a Andrea Pagni. Anclajes, 22(3), 119-135. https:// doi.org/10.19137/anclajes-2018-2239

Fontaine, A. (1982). Andrés Bello, formador de opinión pública. Estudios Públicos, (8), 23-37.

Gillies, R. P. (1851). Memoirs of a literary veteran; including sketches and anecdotes of the most distinguished literary characters from 1794 to 1849 (vol. III). Richard Bentley.

Grases, P. (1973). El Repertorio Americano (Vol. 1). Edición de la Presidencia de la República.

Hammond, P. (1991). John Dryden. A literary life. Macmillan.

Houghton, W. E, Houghton, E. R. y Slingerland, J. H. (Eds.). (1989). The Wellesley Index to Victorian Periodicals 1824-1900. (Vol. v. Epitome and Index. Dated Bibliographies of all Identified Authors and Their Contributions to Major Quarterlies and Monthlies of the Period with a Separate Bibliography of Identified Pseudonyms and Initials). University of Toronto Press, Routledge.

Jaksic, I. (2004). Andrés Bello y la prensa chilena, 1829-1844. En P. Alonso (Ed.), Construcciones impresas. Panfletos, diarios y revistas en la formación de los estados nacionales en América Latina, 1820-1920 (pp. 107-137). Fondo de Cultura Económica.

Jaksic, I. (2010). Andrés Bello: la pasión por el orden. Editorial Universitaria.

Lovera De Sola, R. J. (1981). Bello crítico en Londres. En O. Sambrano Urdaneta (Ed.), Bello y Londres. 
Segundo Congreso del Bicentenario (Tomo II, pp. 7-33). Fundación La Casa de Bello.

Martínez Baeza, S. (2014). Bello y el periodismo. Revista Chilena de Historia y Geografia, (174), 99-120. http://www.schhg.cl/wpschhg/wp-content/uploads/2017/03/Revista-SCHHG-174-1.pdf

Moir, G. (1822). Selections from ancient Spanish poetry. The New Monthly Magazine and Literary Journal, 3, 407-414.

Moir, G. (1824a). Early narrative and lyrical poetry of Spain. The Edinburgh Review, 39, 407-414.

Moir, G. (1824b). Lyric poetry of Spain. The Edinburgh Review, 40, 443-476.

Moir, G. (1832). Minor French Theatre. The Foreign Quarterly Review, 9, 447-455.

Moir, G. (1837). Art. X The bride of Messina; A tragedy, from the German of F.V. Schiller, by George Irvine. The Edinburgh Review, 65(132), 239-251.

Munday, J. (2016). Introducing translation studies. Theories and applications. Routledge.

Murdoch Lawrance, R. (1913). The bards of bon-accord. I. George Moir. En A. L. Moir, Moir genealogy and collateral lines, with historical notes (p. 337). Union Printing Company.

Neaves, C. (1871). The late George Moir. Blackwood's Edinburgh Magazine, 109, 109-117.

Pagni, A. (2003). Traducción del espacio y espacios de la traducción: Les Jardins de Jacques Delille en la versión de Andrés Bello. En F. Schmidt-Welle (ed.) Ficciones y silencios fundacionales. Literaturas y culturas poscoloniales en América Latina (siglo XIX) (pp. 337-356). Iberoamericana/Vervuert. https://doi. org/10.31819/9783865278074-019

Pagni, A. (2004). Olimpio en América del Sur: usos hispanoamericanos del romanticismo francés. Estudios. Revista de Investigaciones Literarias y Culturales, (24), 117-132.

Payàs, G. (2007). La biblioteca chilena de traductores, o el sentido de una colección. En G. Payàs (Ed.), Biblioteca chilena de traductores: ordenada por José Toribio Medina (pp. 23-68). Centro de Investigaciones Diego Barros Arana.

Peers, E. A. (1954). Historia del movimiento romántico español (Tomo I). Gredos.
Poblete, J. (2013). Andrés Bello y la lectura: prácticas autoriales y lectoras en el espacio público americano. En K. Carrillo Zeiter y M. Wehrheim (Eds.) Literatura de la Independencia, independencia de la literatura (pp. 107134). Iberoamericana/Vervuert. https://doi. org/10.31819/9783954871162-006

Pomerlau, M., Echeverri, A. y Bastin, G. L. (2016). HISTAL: una década de investigación sobre la historia de la traducción en América Latina. Eventos, (11), 217-226.

Racine, J. (1834, marzo 29). Ifigenia en Aulide (S. Sanfuentes, Trad.). El Araucano, (135), 3.

Ramicelli, M. E. (2009). Translating cultural paradigms. The role of the Revue Britannique for the first Brazilian fiction writers. En J. Milton y P. Bendia (Eds.), Agents of Translation (pp. 43-61). John Benjamins Publishing Company.

Rodríguez Monegal, E. (1969). El otro Andrés Bello. Monte Ávila Editores.

Rogers, P. (2007). The Cambridge Companion to Alexander Pope. Cambridge University Press.

Shattock, J. (1989). Politics and reviewers. The Edinburgh and The Quarterly in the early Victorian Age. Leicester University Press.

Silva Castro, R. (1958). Prensa y periodismo en Chile (1812-1956). Ediciones de la Universidad de Chile.

Silva Castro, R. (1965). Don Andrés Bello (17811865). Editorial Andrés Bello.

Valero, M. A. (2013). Andrés Bello y sus traducciones de Víctor Hugo: un ejemplo ilustrativo del proceso de construcción de las nuevas literaturas americanas en el proceso de Independencia. Mutatis Mutandis. Revista Latinoamericana de Traducción, 6(1), 43-59.

Valero, M.A. (2001). Andrés Bello traductor. Aproximación a la obra traductológica de Andrés Bello. Núcleo, (18), 181-202.

Veitch, J. (1869). Memoir of Sir William Hamilton, Bart. Edinburgh y William Blackwood and Sons.

Velleman, B. L. (1995). Andrés Bello y sus libros. La Casa de Bello.

Venuti, L. (2000). Translation, community, utopia. En L. Venuti (ed.) The Translation Studies Reader (pp. 468-488). Routledge. 


\section{Anexo 1. Transcripción de la traducción ${ }^{23}$}

Publicado como: Bello, A. (1838, agosto 10). Variedades: "Sobre las traducciones (Del Edinburgh Review)". El Araucano, (415), p. 1. (Extracto traducido de Moir, G. (1837). Art. X The bride of Messina; A Tragedy, from the German of F.V. Schiller, by George Irvine. The Edinburgh Review, 65(132), 239-243).

\section{Sobre las traducciones}

\section{([Extracto] Del Edinburgh Review)}

Todos están convenidos en que la mejor traducción es aquella en que el lector olvida al traductor, y siente lo mismo que si por un súbito encanto tuviese el orijinal a la vista. El lenguaje debe ser tan fácil e idiomático, que nunca surjiera la menor idea de traba o violencia, ni descubra un orijen extraño: debe correr con una fluidez, con una continuidad harmoniosa, cual si formarse en la mente del traductor un todo nuevo y perfectamente homojéneo; debe ser tan natural y tan desnudo de pretensiones, que no llame la atención a sí mismo, sino que como un elemento diáfano se limite a ser el canal de las ideas y sentimientos del autor, y nada más; y al mismo tiempo debe trasladar con exactitud el bosquejo y tintes del orijinal, y transportarnos a un círculo de asociaciones lejanas o extranjeras, colocándonos entre escenas,

"Donde otras voces hablan,

Donde otra perspectiva nos rodea."

Pero la cuestión es ¿cómo podemos llegar o acercarnos más a este grado de perfección? ¿por qué sistema de traducción ha de efectuarse esta alianza de lo extranjero y lo doméstico, de manera que ofrezca al lector que no puede entender el orijinal al trasunto más fiel de las gracias clásicas de la antigüedad, del brillante y pomposo orientalismo de la poesía castellana, de la serena transparencia de la italiana, o del pensativo y caviloso espíritu de la jermánica, o que haga percibir y distinguir en el vehículo de nuestra lengua nativa la concisa grandeza del Dante, el tono tierno, devoto y lirico del Taso, la lozana fantasía y remontado entusiasmo de Calderón?

Toda versión es una especie de compromiso. La animación y la fidelidad literal serian apenas conciliables traduciendo en prosa: cuando el traductor tiene que luchar con los embarazos del verso, y todavía más cuando trata de copiar el ritmo y cadencia métrica del orijinal, esta conciliación es, por descontado imposible. Pero si a la dificultad de verter las palabras por sus equivalentes, y de observar al mismo tiempo las reglas de la versificación, se junta la de expresar toda el alma del orijinal, y de hacer palpable las asociaciones extranjeras, representándolas en algún tipo común, intelijible a todos, fácil es conocer que no solo es imposible la mera traducción literal, sino que para dar el verdadero espíritu, comprensión y fuerza de la obra que se traduce, es necesario que el traductor se desvie hasta cierto punto de la letra.

23 Se ha decidido mantener la ortografía y la puntuación original del texto publicado en El Araucano como también del extracto de la reseña publicada en The Edinburgh Review. Las notas a pie de página corresponden al texto original. 
En este cierto punto es donde está la dificultad, y aunque nadie aspira a lo absolutamente literal, traduciendo en verso, hai con todo dos clases de traductores, que profesan opiniones tan distintas con respecto a la obligación de adherir al orijinal, que podemos caracterizarlos, llamando a los unos literales, según su propia nomenclatura, y a los otros desembarazados y libres. Pero este último epíteto es en muchos casos demasiado favorable:

\section{"Quieren licencia y libertad invocan"}

Entre nosotros la opinion general y la práctica han estado constantemente a favor de las traducciones arreglados a este plan de moderada libertad. En nuestras primeras versiones de escritores clásicos y extranjeros se adoptó ciertamente, o a lo ménos se proclamó, el principio de la fidelidad literal; y en este jénero la traducción de la Jerusalen, por Fairfax, fue una obra maestra. Pero el gran talento de Dryden ${ }^{24}$ produjo una revolución en este punto. Dryden tuvo sin duda muchas de las cualidades mas altas que se requieren en un traductor: conocía suficientemente, si no a fondo, la literatura clásica; manejaba con una consumada destreza todos los recursos de su propia lengua; poseía hasta las más pequeñas y recónditas menudencias del mecanismo métrico, y estaba dotado de un gusto varonil y vigoroso, que le hacía mirar al efecto total mas bien que a las partes, y despreciar el artificio de interpolar ornamentos de su propio fondo, en el tejido de ideas y frases del orijinal. Pero su misma fértil inventiva le incapacitaba de consagrar a sus composiciones de esta clase todo aquel prolijo cuidado que es necesario para trasladar con precisión los conceptos ajenos, en palabras que siendo castizas e idiomáticas, sean al mismo tiempo fieles y literales; en una palabra, para hacer traducciones verdaderas, no parafráticas. No hai duda que algunas veces hasta mejora lo que traduce; pero sucede a menudo que adopta una idea ó jiro análogo donde, con un poco de mas trabajo, hubiera podido dar una copia fiel y animada; $\mathrm{y}$ tambien le vemos muchas veces caer en aquel error, tan común en las que se llaman traducciones libres, de querer evitar la sequedad y tirantez, afectando un aire de novedad y viveza por medio de frases, alusiones y términos técnicos, que se refieren a tiempos y costumbres modernas.

El ejemplo de Dryden fue imitado por Pope ${ }^{25}$ que se apartó, aun mas que su antecesor, de los verdaderos principios del arte de traducir. Pope estaba libre ciertamente de la afectación de frases y voces técnicas de los tiempos modernos; pero cayó en el error todavía más jeneral de querer mejorar a Homero, puliendo sus asperezas, y cubriendo su supuesta desnudez con epítetos e imájenes postizas. Este viciosísimo sistema es, en nuestro sentir, el mas intolerable de todos. Si una obra merece traducirse, tradúzcala tal cual es, con todas sus peculiaridades, por poco que éstas harmonizen con las nociones modernas. La traduccion debe ser una copia del orijinal; no a la verdad una copia chinesca, en que pueda contarse cada pelo de la cabeza y barba de la persona retratada, sino una copia en que nada se quite ni ponga, y en que se conserve la fisonomía característica, sea que esta se conforme o no a la línea de la belleza.

La popularidad de la Iliada y Odisea, de Pope, han producido el efecto mas pernicioso sobre el gusto inglés en materia de traducciones. En realidad, si exceptuamos la de la Iliada, por Cowper, en verso suelto, que, sin embargo, de sus graves defectos de estilo, es una obra concebida, y por lo común, ejecutado, en el verdadero espíritu de lo que debe ser una versión poética, puede decirse que en Inglaterra no apareció traduccion alguna en verso, digna de este nombre, desde el

24 Traductor de La Eneida.

25 Traductor de La Ilíada y La Odisea.

Mutatis Mutandis. Revista Latinoamericana de Traducción Vol. 14, $N .^{\circ} 1,2021$, enero-junio, pp. 92-118 
tiempo de Pope, hasta que se dio a luz la del Dante, por Carey. Fiel y harmoniosa, no tiene otro defecto que el de dejar evaporar las peculiaridades del estilo y verso del Dante en el movimiento del verso suelto a la manera de Milton, elejido por el traductor, porque juzgó imposible imitar en inglés la intrincada estructura de los italianos. El ejemplo que se dio entónces, volviendo al sistema liberal, pero no parafrástico, ha sido despues imitado frecuentemente, y con bastante suceso. Nosotros con todo, preferimos la de la Jerusalen, por Fairfax, a cualquiera de las numerosas traducciones de aquel poema, publicadas en el siglo presente; bien que confesarémos que las de Hunt y Witfen se nos presentan en un contraste favorable con la insípida y miserable de Hoole. La del Orlando Furioso, por Mr. Stewart Rose, reúne el vigor a la fidelidad, y en nuestro sentir ha transportado, en cuanto era dado hacerlo, la deliciosa poesía del Ariosto al idioma no enteramente flexible a que la tradujo.

El vasto campo de la literatura alemana ha llamado recientemente la atencion de no pocos traductores ingleses; y nos inclinamos a creer que las ideas sanas y estrictas que dominan en Alemania sobre el arte de traducir, y la prodijiosa felicidad con que estas ideas se han realizado e ilustrado en aquella literatura, han tenido un influjo mui saludable entre nosotros, corrijiendo la propensión a ese estilo licencioso y meramente imitativo, que Pope había sancionado y popularizado, y restaurando aquel gusto severo, que fue propio de una época mas temprana de nuestras letras, y que miramos como el único que puede interesar largo tiempo. La regla de los mas eminentes traductores alemanes ha sido hundirse enteramente en el orijinal; mirarse como meros intérpretes de los conceptos de un extranjero en la lengua jermánica; abstenerse de añadir o suprimir cosa alguna; no emplear la paráfrasis, donde quiera que pueda traducirse literalmente sin oscuridad ni violencia; copiar, no sólo las ideas, sino, en cuanto cabe, el movimiento de la versificación, el órden de las rimas, y las cadencias del orijinal. Los defectos de las traducciones alemanas son casi siempre tirantez y aspereza, dimanados de una fidelidad excesivamente escrupulosa; pero nadie que no esté iniciado en la literatura alemana puede figurarse hasta qué punto son fieles; y al mismo tiempo animadas y vigorosas las que se han hecho de escritores ingleses y continentales. El viajero inglés que con un cabal conocimiento de la lengua asistiesen en un teatro alemán a la representación de los dramas de Shakspeare, traducidos por Guillermo Schlegel, llegaría casi a figurarse que oía los mismos acentos de nuestro gran poeta dramático, y no solo percibiría los caracteres jenerales de la manera de Shakspeare, sino hasta los tonos peculiares de cada una de sus piezas. Pero lo mas singular es que, no obstante, el gran suceso de Schlegel; otras nuevas versiones de Shakspeare aparecen de tiempo en tiempo en Alemania, y tales algunas de ellas, que, a lo ménos en ciertos dramas, nos sentiríamos inclinados a preferirlas.

Pero hai tantas analogías entre el alemán y el inglés, en cuanto a la lengua y en cuanto al carácter, que el suceso de estas versiones puede mirarse como ménos prodijioso que la destreza y maestria con que los alemanes se han penetrado del espíritu de los poetas de la Península, y lo han transportado a su idioma. Nadie se sorprenderá de encontrar en la del Aminta del Taso, por Jáuregui, una fidelidad literal, en que las palabras de una y otra lengua guardan una exacta correspondencia por líneas enteras. La semejanza entre estas dos lenguas romances, y los muchos rasgos de carácter nacional comunes entreambas, particularmente en la edad anterior, hacen ménos difícil y primorosos la exactitud de Jáuregui, de lo que a primera vista parece. Pero trasladar en acentos teutónicos las palabras del ardiente sur; transportar al vago y meditabundo lenguaje de la Jermania el brillo y fuego de la imajinacion española, infundiéndole las influencias del clima de la Peninsula, es una empresa, que a no ser por las notables traducciones de los dramas de Lope de Vega, Calderón y Moreto, de que puede hacer alarde la literatura alemana, 
nos hubiera parecido imposible. Schlegel fue tambien el que abrió este camino, y ha encontrado dignos sucesores y rivales en Malsburg y Gries, cuyas traducciones de algunas de las mejores piezas de Calderon, están ejecutadas, en una manera y estilo, que, a nuestro juicio, raya con la perfeccion. No solamente se ha hecho la traduccion línea por línea, sino que se han imitado las extrañas singularidades de la versificación castellana, pasando del consonante al asonante, y de éste a aquel, del mismo modo que lo hace el autor, y guardando una misma asonancia por muchos centenares de versos, según las reglas de la métrica española; explayándose luego en las harmoniosas octavas o en la intrincada melodía del soneto; y vertiendo, en fin, toda la variedad de metros que admite la dramática española, en medidas alemanas iguales. Puede decirse, sin temor de contradicción, que el traducir de esta manera una sola pieza de Calderon, es una tarea que exije un grado de paciencia y de laboriosidad, que haría retroceder de espanto a la mayor parte de nuestros traductores ingleses, aun sin tomar en cuenta la vena poética, la delicadeza de percepción, y los profundos conocimientos filolójicos que ella supone.

\section{Anexo 2. Transcripción del texto original}

Extracto de [Moir, G.] (1837). Art. x The bride of Messina; A Tragedy, from the German of F. V. Schiller, by George Irvine. The Edinburgh Review, 65(132), pp. 239-243.

Every one is agreed that the best translation is that, in the perusal of which a foreign reader is enabled to forget the translator, and to feel as if by some sudden charm he were placed in communication with the original. While the language must be so easy and idiomatic as never to suggest the idea of constraint, or of its foreign origin; -so fused into a new whole in the mind of the translator as to flow forth with the charm of a harmonious continuity; so natural and unobtrusive as to attract no attention to itself, but like a colourless and transparent element to be the mere medium of thought and feeling, and nothing more; - it must be made the instrument of rendering with accuracy every outline and tint of the original, - of transporting us into a circle of distant or foreign associations, and of placing us among scenes where other voices speak, and other sights surround.'

But the question is, how is this perfection to be attained, or approached more nearly? By what system of translation is this union of the foreign and domestic to be effected, so as to communicate on the whole to the mere English reader the truest idea of the classic graces of antiquity, the glowing Orientalism of Spanish poetry, the sunny clearness of the Italian, or the pensive and brooding spirit of the German? -or to render the succinct grandeur of Dante, the tender, devoted, and lyric tone of Tasso, the exuberant fancy and soaring enthusiasm of Calderon, all perceptible and distinguishable in the common vehicle of English?

All translation is of course a compromise. To be perfectly literal, and perfectly spirited, would be scarcely practicable in a prose translation; in one where the translator has to encounter the additional trammels of verse, and still more where an attempt is made to copy the rhythm and metrical cadence of the original, it is of course impossible. But when, to the difficulty of rendering mere words by their equivalents, and at the same time observing the rules of versification, is added that of conveying the full significance of the original can only be given by a certain degree of deviation from the letter.

This question of degree, however, occasions the difficulty; and though no one pretends to aim at an absolutely literal version of a foreign writer in poetry, yet there are two classes who entertain 
opinions so distinct in regard to the strictness of adherence to the original required from a translator, that they may fairly enough be characterized as the 'literal,' and (according to their own nomenclature) the 'spirited' or liberal translators. This last epithet, however, we must observe, is in many cases far too favourable; - 'license they mean when they cry liberty;' - and their versions might with justice be characterized as loose rather than spirited.

In England, the prevailing practice and opinion has long been in favour of the liberal system of translation. Our early versions of classic and foreign writers were no doubt framed, professedly at least, on the principle of literal translation; and in this style Fairfax's translation of the Jerusalem was a masterpiece. But a revolution was effected in English translation by the great talent of Dryden. Dryden had undoubtedly many of the highest requisites of a translator; he was a competent if not a profound scholar, and a consummate master of all the resources of the language in which he wrote; -even to the minutest and most secret technicalities of versification: he had a vigorous and masculine taste, which taught him to look to the effect of the whole rather than the parts, and to despise the idea of interweaving with the original texture mere additions and ornaments of his own. But the very fertility and originality of his own mind rendered it difficult for him to devote to his compositions of this kind that patient attention which is required to convey the exact meaning of the original, in words at once idiomatically English, and yet close and literal; -to make his versions, in short, properly translations, as distinguished from paraphrases. Undoubtedly at times he may even improve upon his original, as in his noble version of the line 'Vertitur interea coelum et ruit oceano nox.'

'Mean-time the rapid heavens rolled down the light,

And on the shaded ocean rushed the night.'

But he often adopts a merely analogous turn or idea where a little more pains would have enabled him to represent the original in English words with spirit and fidelity; and he very often falls into that error, so common in what is called spirited translation, of endeavouring to avoid stiffness, and to give an air of vivacity and originality to his version by the employment of phrases, and allusions, and technical expressions connected with modern times and manners, which give to his otherwise noble and beautiful poem something of that slang air which appears so whimsical in Echard's Terence. What can be more absurd, for instance, than the translation of the lines

'Laeva tibi tellus, et longo laeva petantur

Aequora circuito; dextrum fuge littus et undas.

Tack to the larboard, and stand off to sea,

Veer starboard, sea, and land,'-

A counsel which, as Sir Walter Scott justly observes, would probably have been unintelligible not only to Palinurus, but to the best pilot in the British navy.

The questionable example set by Dryden was imitated by Pope, and unfortunately with a still greater deviation from the true principles of translation. From the defect of introducing mere modern phrases into his translation, and thus unpleasingly suggesting the recollections of Wapping in 
the midst of a voyage in the Mediterranean, Pope was, no doubt, free; but he fell into the more cardinal error of translating on the systematic principle of improving his original - softening its rudeness, and hiding its supposed baldness with additional epithets and imagery. For this most vicious system, we own, we have no toleration. If a work is deserving of translation, it deserves to be translated as it is - with all its peculiarities, however little these may be in harmony with modern notions. It ought to be a copy of the original; not, indeed, a Chinese copy, where every hair of the head or eyebrow may be counted in the portrait, but in which nothing is added or taken away, and characteristic expression preserved - whether that happens to correspond with the line of beauty or the reverse.

We believe the popularity of Pope's Iliad and Odyssey to have produced the most pernicious effect upon our English taste as to translation. In fact, with the exception of Cowper's version of the Iliad, in blank verse, which, with considerable defects of style, is yet a work conceived, and in general executed, in a right spirit, we can mention no poetical English translation of any great classic or foreign work, deserving of the name, between the time of Pope and the appearance of Mr Carey's translation of Dante. Mr. Carey's translation was close and harmonious; its only is, that the peculiarities of Dante's manner and versification often evaporate in the Miltonic movement of the blank verse; which the translator (despairing of being able to imitate the intricacies of the terza rima in English) chose to adopt. Since that time, the example thus set of a return to the literal rather than the paraphrastic style of translation has been frequently imitated, and with success. We still prefer, we must admit, Fairfax's version of the Jerusalem to any of the numerous translations of that poem to which the present century has given birth; but those of Hunt and Wiffen certainly present themselves in very favourable contrast with the mawkish and miserable version of Hoole. Mr Stewart Rose's version of the Orlando is remarkably spirited and faithful; and, we really believe, accomplishes as much for Ariosto as we have any reason to think can be done for his delightful verses in the somewhat unbending language to which they have been transferred.

The wide field opened by German literature has of late attracted not a few English translators to that quarter; and we are rather inclined to think that the sound and strict views which prevail in Germany with regard to translation, and the wonderful success with which these views have been carried into execution, and illustrated in their literature, have had a most beneficial effect in correcting the tendency to that loose and merely imitative style which the success of Pope's translations had sanctioned and rendered popular; and of recalling us to a taste for that severer style which distinguished the earlier period of our literature, and which we believe to be the only style of translation which can possess any permanent value or interest. The principle of every German translator of any eminence has long been, to sink himself entirely in his original; to look upon himself as the mere sworn interpreter of a foreigner's meaning, in his own language; to permit himself no liberties either of addition or retrenchment; never to use a mere paraphrase, where without violence or obscurity the meaning of the original can be literally rendered; and to copy not merely the meaning of the passage translated, but, as far as possible, the movement of the versification, the arrangement of the rhymes, the fall of the cadences of the original. The defects of German translations are almost always on the side of ruggedness or stiffness, from too close an adherence to the originals; but no one who has not some acquaintance with German literature can form the least idea of the perfection - both in point of fidelity, and of spirit and freedom, with which some of the German versions, both from our own writers, and from those of the Continent, have been executed. We have more than once alluded to the admirable translation 
of Shakspeare by William Schlegel -a translation in listening to which in a German theatre - the English traveler who has a competent knowledge of the language might almost believe that he heard our great dramatist's own accents; and in which not merely the general characteristics of Shakspeare's manner are caught, but the diversities of tone which distinguish particular plays. But the singular circumstance is, that new translations of Shakspeare still from time to time appear; and excellent as Schlegel's version is, there are some of them to which (in the translation of particular plays at least) we should almost be disposed to award the preference. We have lately perused, in particular, with the highest pleasure, the opening volume of the translation by Philip Kauffman, which is not inferior to that of Schlegel, either in fidelity or poetical beauty, and yet has a quite original and independent character.

There are, however, so many analogies between the German and the English, both in language and character, that the success of these versions of our great dramatist may be considered less remarkable, than the extraordinary skill and mastery with which the Germans have seized and conveyed into their own language the spirit of the poets of the Peninsula. One is not surprised to find, as in Jauregui's Spanish translation of Tasso's Aminta, a version which is almost lite$\mathrm{ral}$, and where sometimes the words in both languages correspond through whole lines. The resemblances between the two Romanic languages, and the many features of national character common to both, particularly at an earlier period, render this by no means so remarkable a tour de force as it might at first sight appear to be. But to embody in Teutonic accents the words of the warm south; to throw into the vague and pensive language of Germany the fire and glow of Spanish imagination, and breathe over it the influences of a Spanish clime, is a task which, but for the remarkable translations from the dramas of Lope de Vega, Moreto, and Calderon, of which German literature can boast, we should beforehand have pronounced to be impossible. In this department also, as in that of the English drama, Schlegel may be said to have led the way; but he has found fit successors and worthy rivals in Malsburg and Gries, both of whom have executed versions of the best of Calderon's plays in a style which to our minds, comes near to perfection. Not merely is the translation executed line for line, but the strange peculiarities of the versification are imitated, - rambling from the full rhyme or consonante into the asonante, or imperfect rhyme, which, when once commenced, must be continued, according to the laws of the Spanish stage, throughout the scene, though consisting, as these frequently do, of many hundred lines; then enlarging into the full stream of harmonious octavas, or terminating (as frequently the soliloquies do) in the intricate melody of the sonnet; - all these, with the many other metres of which the Spanish drama admits, are invariably rendered by corresponding measures in German. It may be safely affirmed, that to render back a single play of Calderon in this style of perfect reflection, is a task involving an amount of patient toil (apart altogether from the poetical feeling and delicacy of perception which it implies, and the previous philological acquisitions which it presupposes) at which most of our English translators would stand aghast.

Cómo citar este artículo: Soltmann, C. (2021). "Sobre las traducciones". El pensamiento traductológico británico en Chile a partir de una traducción de Andrés Bello (1838). Mutatis Mutandis, Revista Latinoamericana, 14(1), 92-118. https://doi.org/10.17533/udea.mut.v14n1a04 